\title{
Analysis of DNA methylation and microRNA expression in NUT (nuclear protein in testis) midline carcinoma of the sinonasal tract: a clinicopathological, immunohistochemical and molecular genetic study
}

\author{
J. LACO ${ }^{1, *}$, H. KOVARIKOVA ${ }^{2}$, M. CHMELAROVA ${ }^{2}$, H. VOSMIKOVA ${ }^{1}$, K. SIEGLOVA $^{1}$, I. BUBANCOVA ${ }^{2}$, P. DUNDR ${ }^{3}$, K. NEMEJCOVA ${ }^{3}$, J. MICHALEK ${ }^{4}$, \\ P. CELAKOVSKY ${ }^{5}$, R. MOTTL ${ }^{6}$, I. SIRAK ${ }^{7}$, M. VOSMIK ${ }^{7}$, I. MAREK ${ }^{8}$, T. GERYK ${ }^{1}$, J. MEJZLIK ${ }^{5}$, J. SATANKOVA ${ }^{5}$, A. RYSKA ${ }^{1}$
}

\begin{abstract}
${ }^{1}$ The Fingerland Department of Pathology, Charles University, Faculty of Medicine and University Hospital in Hradec Kralove, Czech Republic; ${ }^{2}$ Institute for Clinical Biochemistry and Diagnostics, Charles University, Faculty of Medicine and University Hospital in Hradec Kralove, Czech Republic; ${ }^{3}$ Department of Pathology, Charles University, First Faculty of Medicine and General University Hospital in Prague, Czech Republic; ${ }^{4}$ Department of Clinical and Molecular Pathology, Palacky University, Faculty of Medicine and Dentistry and University Hospital Olomouc, Czech Republic; ${ }^{5}$ Department of Otorhinolaryngology and Head and Neck Surgery, Charles University, Faculty of Medicine and University Hospital in Hradec Kralove, Czech Republic; ${ }^{6}$ Department of Dentistry, Charles University, Faculty of Medicine and University Hospital in Hradec Kralove, Czech Republic; ${ }^{7}$ Department of Oncology and Radiotherapy, Charles University, Faculty of Medicine and University Hospital in Hradec Kralove, Czech Republic; ${ }^{8}$ Department of Orthodontics, Clinic of Dental Medicine, Palacky University, Faculty of Medicine and Dentistry and University Hospital Olomouc, Czech Republic
\end{abstract}

${ }^{*}$ Correspondence: lacoj@lfhk.cuni.cz

Received November 22, 2016 / Accepted April 20, 2017

\begin{abstract}
The aim of this study was a detailed clinicopathological investigation of sinonasal NUT midline carcinoma (NMC), including analysis of DNA methylation and microRNA (miRNA) expression. Three (5\%) cases of NMC were detected among 56 sinonasal carcinomas using immunohistochemical screening and confirmed by fluorescence in situ hybridization. The series comprised 2 males and 1 female, aged 46, 60, and 65 years. Two tumors arose in the nasal cavity and one in the maxillary sinus. The neoplasms were staged pT1, pT3, and pT4a (all cN0M0). All patients were treated by radical resection with adjuvant radiotherapy. Two patients died 3 and 8 months after operation, but one patient (pT1 stage; R0 resection) experienced no evidence of disease at 108 months. Microscopically, all tumors consisted of infiltrating nests of polygonal cells with vesicular nuclei, prominent nucleoli and basophilic cytoplasm. Abrupt keratinization was present in only one case. Immunohistochemically, there was a diffuse expression of cytokeratin (CK) cocktail, CK7, p40, p63, and SMARCB1/INI1. All NMCs tested negative for EBV and HPV infection. Two NMCs showed methylation of RASSF1 gene. All other genes (APC, ATM, BRCA1, BRCA2, CADM1, CASP8, CD44, CDH13, CDKN1B, CDKN2A, CDKN2B, CHFR, DAPK1, ESR1, FHIT, GSTP1, HIC1, KLLN, MLH1a, MLH1b, RARB, TIMP3, and VHL) were unmethylated. All NMCs showed upregulation of miR-9 and downregulation of miR-99a and miR-145 and two cases featured also upregulation of miR-21, miR-143, and miR-484. In summary, we described three cases of sinonasal NMCs with novel findings on DNA methylation and miRNA expression, which might be important for new therapeutic strategies in the future.
\end{abstract}

Key words: sinonasal tract, NUT midline carcinoma, $t(15 ; 19)$ translocation, DNA methylation, RASSF1, microRNA

NUT midline carcinoma (NMC) is defined as any malignant epithelial tumor with rearrangement of the NUT (nuclear protein in testis) gene (also known as NUTM1 (NUT midline carcinoma family member 1)) on chromosome $15 q 14$ [1]. In approximately two thirds of cases, the translocation partner is the BRD4 (bromodomain containing 4) gene on chromosome 19p13.1, creating a new BRD4-NUT fusion oncogene that markedly disrupts squamous differentiation and promotes tumorigenesis. In the remaining one third of cases, the NUT gene is fused to another member of the BET (bromodomain and extra-terminal motif) family, the BRD3 gene on chromosome $9 \mathrm{q} 34.2$, or to other yet uncharacterized genes $[2,3]$.

NMC is thought to be a very rare neoplasm but its exact prevalence remains unknown and it is generally presumed that it is almost certainly underdiagnosed. However, with a new highly sensitive and specific monoclonal antibody to the NUT protein that has recently become commercially avail- 
able, the recognition of NMC is greatly simplified [4]. Regardless of improved diagnostics, NMC will probably remain an uncommon neoplasm. For example, it constituted only $7 \%$ of 98 poorly differentiated carcinomas, occurring in patients under the age of 40 [5]. Similarly, Bishop and Westra found only $3(2 \%)$ NMCs among 151 primary sinonasal carcinomas from their archives [6]. NMC has been documented in both males and females of all ages, from newborns to those aged over 80 years $[1,7,8]$. In most cases, NMC occurs in the midline anatomic areas, such as the sinonasal tract and the mediastinum [1]. NMC is a particularly aggressive neoplasm that is almost invariably fatal - the median overall survival is only 9-10 months despite multimodal treatment [9].

Apart from the defined NUT gene rearrangement, other molecular genetic characteristics of NMC are largely unknown. Because of its poor prognosis, an intensive search for new therapeutic strategies based on better understanding of genetic alterations occurring in this malignancy is therefore critical. Epigenetic changes, the most common of which being methylation of $\mathrm{CpG}$ islands in the promoter gene region, significantly contribute to malignant transformation and progression $[10,11]$. Similarly, microRNAs (miRNAs) which are short non-coding RNA molecules primarily functioning as negative regulators of translation may target several oncogenes and tumor suppressor genes and thereby play important role in the tumorigenesis [12]. In sinonasal tumors and in NMC in particular, however, that kind of research has drawn little attention of investigators so far [13-15].

Table 1. List of primary antibodies.

\begin{tabular}{lccc}
\hline Antibody & Clone & Dilution & Source \\
\hline CD34 & QBEnd10 & $1: 50$ & Dako \\
CD56 & MRQ-42 & $1: 2000$ & Cell Marque \\
Chromogranin & Polyclonal & $1: 200$ & Novocastra \\
CK & AE1/AE3 & $1: 100$ & Dako \\
CK5/6 & D5/16 B4 & $1: 100$ & Dako \\
CK7 & OV-TL 12/30 & $1: 100$ & Dako \\
EMA & E29 & $1: 400$ & Dako \\
Ki-67 & $30-9$ & Pre-diluted & Ventana \\
NUT & C52B1 & $1: 50$ & Cell Signaling \\
p16 & E6H4 & Pre-diluted & Ventana \\
p40 & Polyclonal & $1: 250$ & Zytomed \\
p63 & 4 A4 & Pre-diluted & Ventana \\
S100 & Polyclonal & $1: 5000$ & Dako \\
SMARCB1(INI1) & MRQ-27 & $1: 250$ & Cell Marque \\
Synaptophysin & SP11 & Pre-diluted & Ventana \\
Vimentin & V9 & $1: 400$ & Dako \\
\hline
\end{tabular}

Abbreviations: $\mathrm{CK}=$ cytokeratin; $\mathrm{EMA}=$ epithelial membrane antigen; NUT $=$ nuclear protein in testis; SMARCB1/INI1 = SWI/SNF-related matrix-associated actin-dependent regulator of chromatin subfamily B member 1/integrase interactor 1

Sources: Cell Marque/Sigma-Aldrich (Rocklin, CA, USA); Cell Signaling Technology (Danvers, MA, USA), Dako (Glostrup, Denmark); Novocastra/Leica Biosystems (Newcastle upon Tyne, UK); Ventana/Roche (Basel, Switzerland); Zytomed Systems GmBH (Berlin, Germany)
The aim of this study was to investigate NUT protein expression in a large cohort of sinonasal carcinomas diagnosed over a long period at three university departments of pathology and to expand the clinicopathologic and molecular genetic characteristics of sinonasal NMC. For this purpose, we performed promoter gene DNA methylation analysis of selected tumor suppressor genes by means of methylation-specific multiplex ligation-dependent probe amplification (MS-MLPA) and of methylation-specific polymerase chain reaction (MSP) and expression analysis of selected miRNAs using quantitative real-time polymerase chain reaction (qRT-PCR). To the best of our knowledge, such investigation has not been performed in NMC so far.

\section{Patients and methods}

Clinicopathological data. A review of the surgical pathology files at The Fingerland Department of Pathology (University Hospital, Hradec Kralove, Czech Republic), Department of Pathology (General University Hospital, Prague, Czech Republic), and Department of Pathology (University Hospital, Olomouc, Czech Republic) identified all malignant epithelial tumors of the sinonasal tract consecutively diagnosed between August 1995 and August 2014. As no neoplasms arose in the frontal and sphenoid sinuses, only tumors primarily originating from the nasal cavity, maxillary sinuses and ethmoid complex were included [16]. Among the total of 73 cases diagnosed during the period, 17 tumors were classified as adenocarcinomas $(7 \times$ adenoid cystic, $5 \times$ intestinal-type, $5 \times$ low-grade non-intestinal-type) and excluded from the series, because none of these tumor types were found to be NUT-positive in a previous study [6]. Thus, the study sample comprised 56 tumors. Paraffin blocks for further analysis were available in all cases. Ethical approval was obtained from the Ethics Committee, University Hospital, Hradec Kralove (Reference No. 201602 I118P).

For every patient, gender, age at the time of diagnosis, smoking history (non-smoker vs. ex-smoker vs. current smoker), occupation (risky vs. non-risky), tumor localization, and pathological TNM staging were recorded [16]. In cases with radical surgery not performed, clinical TNM staging was used. During the follow-up period (until August 2016), local recurrence, regional recurrence, distant recurrence, death, and tumor-related death were recorded. Treatment modalities included radical surgery, radiotherapy, and chemotherapy in various combinations.

As controls, we examined 10 mucosal specimens from the nasal cavity and maxillary sinus with features of chronic rhinitis and sinusitis, obtained from 5 males and 5 females aged $24-62$ years (median 45 years; mean $44 \pm 15$ years).

Immunohistochemical examination (IHC). All tumors were first tested for NUT protein expression. As previously described, only cases showing diffuse strong nuclear expression in more than $50 \%$ of tumor cells were regarded positive 
$[4,6]$. Additional IHC using antibodies listed in Table 1 was performed on NUT-positive cases only.

Two mm-thick sections were cut from full section paraffin blocks, mounted on slides coated with 3-aminopropyltriethoxy-silane, deparaffinized in xylene and rehydrated in descending grades (100\% to $70 \%$ ) of ethanol. The staining of all antibodies was performed using immunostainer BenchMark ULTRA (Ventana/Roche, Basel, Switzerland), with ultraView Universal DAB Detection Kit, Bluing Reagent and Hematoxylin II (all Ventana/Roche) as visualization reagent and chromogen. Appropriate positive and negative controls were used. In particular, normal testis served as both positive (germ cells) and negative (non-germ cells) control for NUT.

Fluorescence in situ hybridization (FISH). All NUT-positive tumors detected by IHC were further tested for NUT gene rearrangement. FISH was performed as previously described $[17,18]$. Briefly, $4-\mu \mathrm{m}$-thick section was routinely deparaffinized, incubated in the Heat Pretreatment Solution Citric (pH 6.0) (ZytoVision GmbH, Bremerhaven, Germany) for $15 \mathrm{~min}$ at $98^{\circ} \mathrm{C}$ and digested in protease solution with Pepsin Solution (ZytoVision) at $37^{\circ} \mathrm{C}$ for 5 min. After dehydration, a volume of $10 \mu \mathrm{L}$ of the ZytoLight ${ }^{\bullet}$ SPEC NUTM1 Dual Color Break Apart Probe (ZytoVision) was applied. The slide was than incubated in the Dako Hybridizer (Dako) with co-denaturation parameters $75^{\circ} \mathrm{C}$ for $10 \mathrm{~min}$ and hybridization parameters $37^{\circ} \mathrm{C}$ for $16 \mathrm{~h}$. Posthybridization wash was performed in the $25 \mathrm{x}$ Wash Buffer $\mathrm{A}$ (ZytoVision) at $37^{\circ} \mathrm{C}$ twice for $5 \mathrm{~min}$. Then, the slides were dehydrated, counterstained with DAPI/Dura Tect ${ }^{\mathrm{Tw}}$-Solution (ZytoVision), cover-slipped and immediately examined.

Each specimen was examined with a Nikon Eclipse 80i fluorescence microscope using a $100^{\prime}$ objective and triple or single bandpass filter sets (ZyBlue/ZyGreen/ZytoOrange; ZyGreen; ZyOrange). Scoring was done by counting the number of fluorescent signals in 100 randomly selected non-overlapping tumor cell nuclei. Normal NUT gene status was defined as presence of two orange/green fusion signals representing two non-arranged $15 \mathrm{q} 14$ loci in a single nucleus. NUT gene rearrangement was indicated by presence of one non-arranged orange/green fusion signal, one separate orange and one separate green signal in a single nucleus. The case was considered FISH positive when more than $20 \%$ of tumor cells showed NUT rearrangement [4].

Methylation-specific multiplex ligation-dependent probe amplification (MS-MLPA). All NUT-positive tumors detected by IHC were further tested by the MS-MLPA probe set ME001 (MRC-Holland, Amsterdam, The Netherlands), which can simultaneously check for aberrant methylation in 24 tumor suppressor genes (APC, ATM, BRCA1, BRCA2, CADM1, CASP8, CD44, CDH13, CDKN1B, CDKN2A, CDKN2B, CHFR, DAPK1, ESR1, FHIT, GSTP1, HIC1, KLLN, MLH1a, MLH1b, RARB, RASSF1a, RASSF1b, TIMP3, TP73, $V H L)$. Probe sequences, gene loci and chromosome locations can be found at http://www.mlpa.com. Individual genes were evaluated by two probes which recognized different Hhal restriction sites in their regions. The experimental procedure was carried out according to the manufacturer's instructions, with minor modifications as previously described [14].

In brief, DNA (100 ng) was dissolved in $5 \mu \mathrm{L}$ TE-buffer $(10 \mathrm{mM}$ Tris $\bullet \mathrm{Cl} ; 0.5 \mathrm{mM}$ EDTA; $\mathrm{pH} 9.0)$, denatured and subsequently cooled down to $25^{\circ} \mathrm{C}$. After adding the probe mix, the probes were allowed to hybridize overnight at $60^{\circ} \mathrm{C}$. Subsequently, the samples were divided into two: in one half, the samples were directly ligated, while for the other half ligation was combined with the Hhal digestion enzyme. This digestion resulted in ligation of the methylated sequences only. PCR was performed on all the samples using a standard thermal cycler GeneAmp 9700 (Applied Biosystems, Foster City, CA, USA), with 35 cycles of denaturation at $95^{\circ} \mathrm{C}$ for $30 \mathrm{~s}$, annealing at $60^{\circ} \mathrm{C}$ for $30 \mathrm{~s}$ and extension at $72^{\circ} \mathrm{C}$ for $1 \mathrm{~min}$, with a final extension of $20 \mathrm{~min}$ at $72^{\circ} \mathrm{C}$. Aliquots of $0.6 \mu \mathrm{L}$ of the PCR reaction were combined with $0.2 \mu \mathrm{L}$ LIZ-labeled internal size standard (Applied Biosystems), and $9.0 \mu \mathrm{L}$ deionized formamide. After denaturation, fragments were separated and quantified by electrophoresis on an ABI 3130 capillary sequencer and analyzed using GeneMapper4.0 (both Applied Biosystems). Peak identification and values corresponding to peak size in base pairs (bp), and peak areas were used for further data processing. Methylation dosage ratio was obtained by the following calculation: $\mathrm{Dm}=(\mathrm{Px} / \mathrm{Pctrl}) \mathrm{Dig} /$ (Px/Pctrl)Undig, where Dm is the methylation dosage ratio, Px is the peak area of a given probe, Pctrl is the sum of the peak areas of all control probes, Dig stands for Hhal digested sample and Undig for undigested sample. Dm can vary between 0 and 1.0 (corresponding to $0-100 \%$ of methylated DNA). Based on previous experiments, promoter was considered to be methylated if the dosage ratio was $\geq 0.20$, which corresponds to $20 \%$ of methylated DNA [19]. CpG universal methylated and unmethylated DNA (Zymo Research Corporation, Irvine, CA, USA) was used in every run as controls.

Methylation-specific polymerase chain reaction (MSP). All genes showing methylation using MS-MLPA (i.e. RASSF1a, RASSF1b, and TP73 - see Results) were further tested by means of MSP for confirmation. MSP requires bisulfite treatment of genomic DNA. It is used for conversion of all unmethylated cytosines to uracils, leaving methylated cytosines unaffected.

A total of 500 ng of genomic DNA was treated with bisulfite using the EZ DNA Methylation-Gold ${ }^{\mathrm{m}}$ Kit according to the manufacturer's protocol (Zymo Research Corporation). MSP was performed on the Rotor-Gene Q (Qiagen, Hilden, Germany) in two types of reaction mixture within one run, for amplifying methylated and unmethylated DNA, respectively. Primers were designed using MethPrimer with consideration of the MS-MLPA probe locations and the FFPE DNA fragmentation. Primer sequences with annealing temperatures and amplicon lengths are listed in Table 2. MSP reaction mixture contained 10x PCR Buffer, $\mathrm{MgCl}_{2}(25 \mathrm{mM})$, dNTPs solution Takara $(2.5 \mathrm{mM})$, primers $(10 \mu \mathrm{M})$, Platinum ${ }^{\bullet}$ Taq DNA Polymerase (Invitrogen by 
Table 2. Methylation-specific PCR primer sequences.

\begin{tabular}{|c|c|c|c|c|}
\hline Gene & Primer sequence $5^{\prime}-$ & & Amplicon size (bp) & Annealing temperature $\left({ }^{\circ} \mathrm{C}\right)$ \\
\hline \multirow{2}{*}{ RASSF1a* } & methylated DNA & $\begin{array}{l}\text { Fw: TTAGGTTTTTATTGCGCGG } \\
\text { Rv: CCGTACTTCGCTAACTTTAAACG }\end{array}$ & 138 & 60 \\
\hline & unmethylated DNA & $\begin{array}{l}\text { Fw: ATTTAGGTTTTTATTGTGTGG } \\
\text { Rv: CCATACTTCACTAACTTTAAACACT }\end{array}$ & 140 & 57 \\
\hline \multirow{2}{*}{ 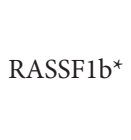 } & methylated DNA & $\begin{array}{l}\text { Fw: GCGGGTTTCGATTTTAGC } \\
\text { Rv: CTACACCCAAATTTCCATTACG }\end{array}$ & 90 & 60 \\
\hline & unmethylated DNA & $\begin{array}{l}\text { Fw: AGGGTGGGTTTTGATTTTAGTG } \\
\text { Rv: CTACACCCAAATTTCCATTACAC }\end{array}$ & 93 & 57 \\
\hline \multirow{2}{*}{$\mathrm{TP}^{*} 3^{* *}$} & methylated DNA & $\begin{array}{l}\text { Fw: CGCGTTTATATAATTCGTTTAGG } \\
\text { Rv: GAACCCCGATTTCGCTAC }\end{array}$ & 110 & 60 \\
\hline & unmethylated DNA & $\begin{array}{l}\text { Fw: TTTTTTGTGTTTATATAATTTGTTTA } \\
\text { Rv: CAAACCCCAATTTCACTAC }\end{array}$ & 116 & 57 \\
\hline
\end{tabular}

${ }^{*}$ Primers designed with consideration of the MS-MLPA probe location. ${ }^{* *}$ Primers designed to the neighboring CpG sites of the MS-MLPA probe location. Abbreviations: MS-MLPA = methylation-specific multiplex ligation-dependent probe amplification; PCR = polymerase chain reaction

Life Technologies - Thermo Fisher Scientific, USA), SYTO 9 Dye $(0.05 \mathrm{mM})$, bisulfite converted DNA and water. Each run included a bisulfite-converted universal methylated and unmethylated DNA (Qiagen) and a no-template control. Fluorescence data were analyzed using Rotor-Gene Q software. Amplicon was considered as methylated when there was amplification in reaction mixture with methylated primers of both types of reaction mixture. When there was amplification only in mixture with primer pair for unmethylated DNA, the amplicon was considered as unmethylated.

Detection of miRNA expression. The selection rule of miRNA analyzed was based on results of previous studies investigating miRNA expression in head and neck carcinomas, as reviewed in a recent article by Kovaříková et al. [12]

Five- $\mu \mathrm{m}$-thick sections were cut from formalin fixed, paraffin embedded (FFPE) tissue samples and deparaffinized using xylene and ethanol. Total RNA, including miRNAs, was isolated using RNeasy FFPE Kit (Qiagen, Valencia, CA, USA) according to the manufacturer's protocol. The extracted RNA was eluted in $30 \mu \mathrm{L}$ of RNase-free water. The concentration and purity of the isolated RNA was determined by NanoDrop ND 1000 spectrophotometer (Thermo Fisher Scientific, Wilmington, DE, USA) by measuring the optical density at $260 \mathrm{~nm}$ and $280 \mathrm{~nm}$ (A260/280 ratio). After the isolation, the samples were immediately processed or stored at $-70^{\circ} \mathrm{C}$.

The synthesis of cDNA was done using TaqMan ${ }^{\circ}$ Advanced miRNAcDNASynthesis Kitwith universal reversetranscription primers (Applied Biosystems, Foster City, CA, USA) according to the manufacturer's protocol with 8-10 ng of total RNA into the reaction. Real-time PCR was performed using TaqMan ${ }^{\circ}$ Fast Advanced Master Mix (Applied Biosystems) and specific TaqMan ${ }^{\odot}$ Advanced miRNA Assays (Applied Biosystems) on Rotor-Gene Q (Qiagen). Assays hsa-miR-9, hsa-miR-21, hsa-miR-99a, hsa-miR-143, hsa-miR-145, hsa-miR-484, and hsa-miR-361 (endogenous control) were used. All steps were performed by following the manufacturer's protocol.

All reactions were performed in triplicates; the reaction volume was $10 \mu \mathrm{L}$ with $2.5 \mu \mathrm{L}$ of the sample. The reaction conditions were set according to the manufacturer's protocol as follows: enzyme activation at $95^{\circ} \mathrm{C}$ for $20 \mathrm{~s}$, followed by 40 cycles of denaturation at $95^{\circ} \mathrm{C}$ for $3 \mathrm{~s}$ and annealing/extension at $60^{\circ} \mathrm{C}$ for $30 \mathrm{~s}$. Data obtained from the reaction were analyzed using the Rotor-Gene Q Series Software. Relative expression of each miRNA was determined by the $2^{-\Delta \Delta \mathrm{Ct}}$ method; expression levels of miR-361 served for data normalization [20]. This method was chosen based on literature review and manufacturer's recommendation for endogenous controls listed in the user guide for TaqMan ${ }^{\circ}$ Advanced miRNA Assays.

Epstein-Barr virus (EBV) and human papillomavirus (HPV) detection. All NUT-positive tumors detected by IHC were further tested for presence of EBV and HPV infection.

For detection of EBV, CISH using the EBER 1 DNP Probe (Ventana/Roche) was performed in the immunostainer BenchMark ULTRA (Ventana/Roche), with ISH iVIEW Blue Plus Detection Kit as a visualization reagent and chromogen. HPV DNA detection was performed by real-time PCR with the AmoyDx Human Papillomavirus Genotyping Detection Kit (Amoy Diagnostics Co., Xiamen, Fujian, China) according to the manufacturer's protocol as previously described [21]. The test is designed for detection and genotyping of 19 highrisk HPV types (HPV16, 18, 26, 31, 33, 35, 39, 45, 51, 52, 53, $56,58,59,66,68,70,73$, and 82 ) and 2 low-risk HPV types (HPV6 and 11).

Statistical analysis. Basic descriptive statistics were adopted for the analysis: median, mean, and 95\% confidence interval for continuous data, and absolute and relative frequencies for categorical data. All statistical analyses were performed using the NCSS 8 statistical software program (NCSS, Kaysville, Utah, USA).

\section{Results}

Clinical data. Among 56 sinonasal carcinomas diagnosed over a 19 year period, three (5\%) cases were diagnosed as NMC using IHC. The patients' clinical data are listed in Table 3 . The tumors occurred in 2 males and 1 female, aged 
Table 3 Clinical data of patients with NUT midline carcinomas.

\begin{tabular}{|c|c|c|c|c|c|c|c|c|c|}
\hline No & $\begin{array}{l}\text { Gender/ } \\
\text { Age (y.) }\end{array}$ & Smoking & Location & TNM & Treatment & $\begin{array}{l}\text { Resection } \\
\text { margins }\end{array}$ & $\begin{array}{l}\text { Follow-up } \\
\text { (months) }\end{array}$ & $\begin{array}{l}\text { Follow-up } \\
\text { result }\end{array}$ & Original diagnosis \\
\hline 1 & $\mathrm{~F} / 60$ & Smoker & Nasal cavity & T4aN0M0 & Surgery + RT & Positive & 3 & DOD & NK-SCC \\
\hline 2 & $\mathrm{M} / 65$ & Non-smoker & Nasal cavity & T1N0M0 & Surgery + RT & Negative & 108 & NED & NK-SCC \\
\hline 3 & $\mathrm{M} / 46$ & Smoker & Maxillary sinus & T3N0M0 & Surgery + RT & Positive & 8 & DOD & Basaloid SCC \\
\hline
\end{tabular}

Abbreviations: $\mathrm{DOD}=$ died of disease; $\mathrm{F}=$ female; $\mathrm{M}=$ male; $\mathrm{NED}=$ no evidence of disease; $\mathrm{NK}=$ nonkeratinizing; $\mathrm{NUT}=$ nuclear protein in testis; $\mathrm{RT}=$ radiotherapy; SCC $=$ squamous cell carcinoma

Table 4. Immunohistochemical characteristics of NUT midline carcinomas.

\begin{tabular}{|c|c|c|c|c|c|c|c|c|}
\hline No & $\begin{array}{l}\text { CK } \\
(\%)\end{array}$ & $\begin{array}{c}\text { CK5/6 } \\
(\%)\end{array}$ & $\begin{array}{l}\text { CK7 } \\
(\%)\end{array}$ & $\begin{array}{c}\text { EMA } \\
(\%)\end{array}$ & $\begin{array}{l}\text { p16 } \\
(\%)\end{array}$ & $\begin{array}{c}\mathrm{p} 40 / \mathrm{p} 63 \\
(\%)\end{array}$ & $\begin{array}{c}\text { SMARCB1(INI1) } \\
(\%)\end{array}$ & $\begin{array}{c}\text { Vimentin } \\
(\%)\end{array}$ \\
\hline 1 & 100 & 100 & 100 & 0 & 70 & $100 / 100$ & 100 & 2 \\
\hline 2 & 100 & 5 & 70 & 10 & 40 & $70 / 90$ & 100 & 5 \\
\hline 3 & 100 & 90 & 0 & 20 & 10 & $100 / 100$ & 100 & 5 \\
\hline
\end{tabular}

Abbreviations: $\mathrm{CK}=$ cytokeratin; EMA = epithelial membrane antigen; NUT = nuclear protein in testis; SMARCB1/INI1 = SWI/SNF-related matrix-associated actin-dependent regulator of chromatin subfamily B member 1/integrase interactor 1; \% - percentage of positive tumor cells

46,60 , and 65 years (mean $57 \pm 10$ years). Two patients were smokers and one non-smoker. None of the patients experienced occupational exposure to risky chemical substances. Two tumors arose in the nasal cavity $(1 \times$ right, $1 \times$ left $)$ and one in the right maxillary sinus. The neoplasms were diagnosed in stage pT1, pT3, and pT4a. None of the patients had regional or distant metastases at the time of diagnosis (cN0cM0). All patients were treated by radical surgical resection $(2 \times$ positive and $1 \times$ negative resection margins) with adjuvant radiotherapy. None of the patients developed regional or distant metastases during the follow-up period ranging 3-108 months (median 8 months; mean 40 \pm 59 months). Ultimately, two patients died due to the tumor 3 and 8 months after the operation, but one patient (pT1cN0cM0 with negative resection margins) featured no evidence of disease on the last follow-up control at 108 months.

Microscopic findings. Two NMCs were originally diagnosed as non-keratinizing conventional squamous cell carcinoma (NK-SCC) and one as basaloid SCC. The tumors consisted of infiltrating nests, cords or sheets of polygonal cells with round to oval, frequently vesicular nuclei with prominent one or more nucleoli, and with moderate amount of basophilic cytoplasm (Figure 1a, 1b). Spindling of the tumor cells was not seen. Rhabdoid cells were absent. Mitotic activity was extremely high, reaching up to 85 mitotic figures (mf) per $10 \mathrm{HPFs}$. Apoptotic bodies were also frequently present. Despite these high grade features, however, the tumor cells lacked significant pleomorphism. In all cases, central comedo-type necrosis was easily found. Abrupt keratinization, i.e. presence of keratinizing cells with eosinophilic cytoplasm immediately adjacent to the undifferentiated cells, was observed in only one tumor (No. 1), occupying about $30 \%$ of the neoplasm (Figure 1c). Formation of glands or rosettes was not seen. Vascular invasion was obvious in all cases, whereas perineural spread was absent. Infiltration of the bone was evident in two cases (Nos 1, 3). The stroma was composed of unremarkable fibrous tissue without significant inflammatory infiltrate. Spread of tumor cells into mucosal epithelium, or, alternatively, pre-existing in situ lesion - was observed in only one case (No. 1) (Figure 1d).

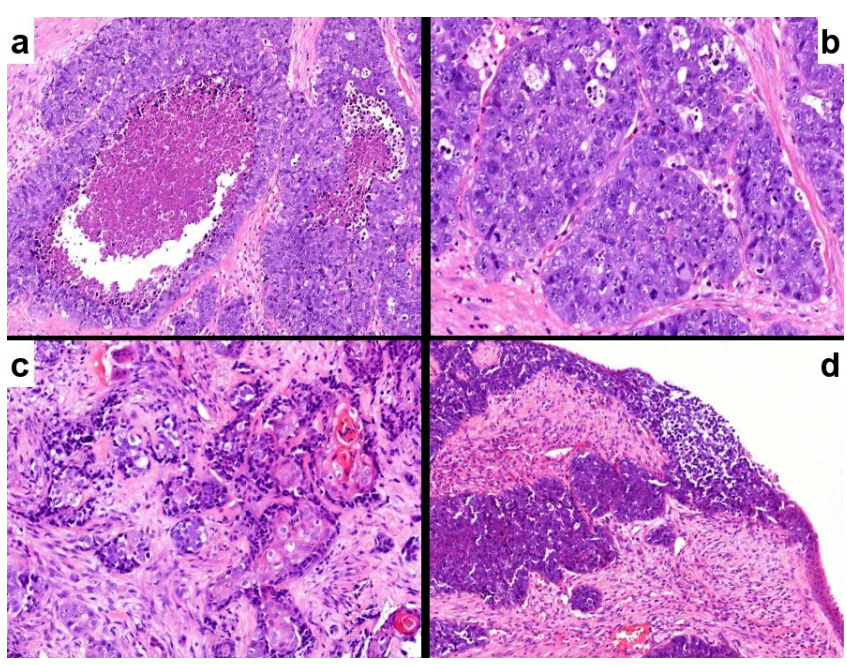

Figure 1. Microscopic features of NUT midline carcinomas. a) Tumor cells grow in larger nests with central comedo-type necrosis (hematoxylin-eosin (HE), original magnification $200 \times$ ). b) Tumor cells have enlarged vesicular nuclei with prominent nucleoli and basophilic cytoplasm. Numerous mitotic figures and apoptotic bodies are evident (HE, original magnification $400 \times$ ). c) Abrupt keratinization - larger cells with eosinophilic cytoplasm are surrounded by undifferentiated cells. Notice small keratin pearls in upper and lower right corner (HE, original magnification 300x). d) Sharp transition between normal mucosal epithelium (lower right) and dysplastic epithelium in continuity with invasive tumor - pre-existing in situ lesion or secondary involvement? (HE, original magnification $200 \times$ ) 


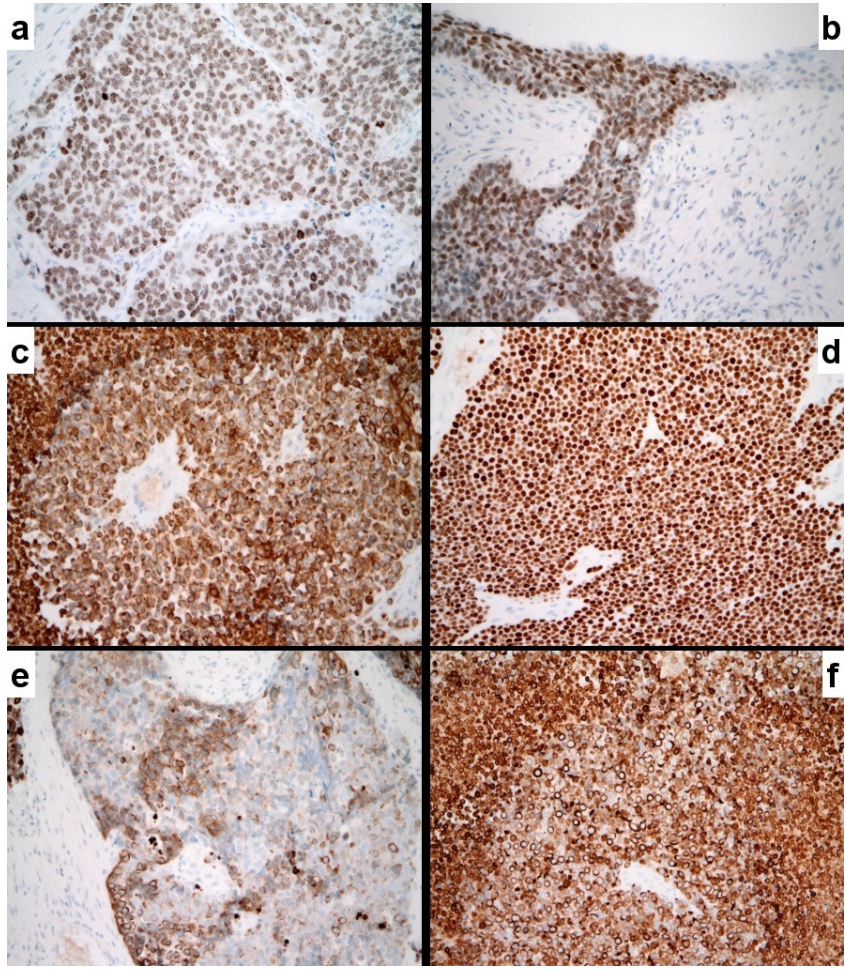

Figure 2. Immunohistochemical characteristics of NUT midline carcinomas. a) Diffuse speckled nuclear expression of NUT in tumor cells. b) Dysplastic epithelium and invasive carcinoma are diffusely NUT positive, while normal surface epithelium is negative (upper right). c) Diffuse expression of cytokeratin (CK) cocktail. d) Diffuse nuclear expression of p63 in tumor cells. Expression pattern of p40 was similar. e) Focal expression of CK5/6 in tumor cells. f) Diffuse expression of CK7 in tumor cells. (Original magnification (a-f) 400x)

Immunohistochemical findings. All NMCs showed diffuse nuclear expression of this marker in more than $90 \%$ of tumor cells (Figure 2a), with some signal weakening in areas with abrupt keratinization. The "in situ" component seen in one case displayed NUT expression as well (Figure 2b). All NUT-negative tumors completely lacked any staining. The results of IHC analysis regarding NMC are listed in Table 4. In all cases, there was (nearly) diffuse expression of cytokeratin $(\mathrm{CK})$ cocktail (Figure 2c), p40, p63 (Figure 2d), and SMARCB1 (INI1) and variably focal expression of CK5/6 (Figure 2e), epithelial membrane antigen (EMA), p16, and vimentin. In two tumors, we observed nearly diffuse

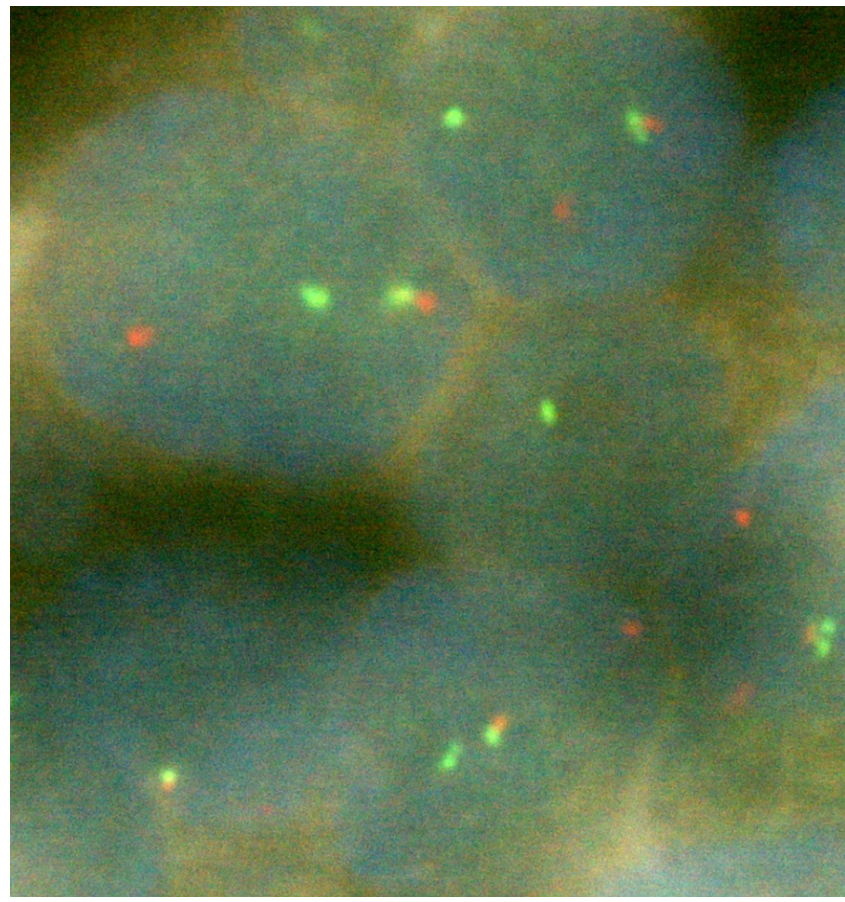

Figure 3. Fluorescence in situ hybridization shows one non-arranged orange/green fusion signal, one separate orange and one separate green signal within tumor cell nuclei, indicating rearrangement of NUT gene. (Original magnification 1000x)

expression of CK7 (Figure 2f), whereas it was absent in the remaining case. Proliferation index Ki-67 was higher than 95\%. Expression of all other tested antibodies (CD34, CD56, chromogranin, S100, and synaptophysin) was absent.

Molecular genetic findings and results of EBV and HPV detection. The results are summarized in Tables 5 and 6. FISH revealed rearrangement of NUT gene in all three NMCs, each case showing split signals in more than 90/100 tumor cells (Figure 3).

Results of methylation analysis of 24 selected tumor suppressor genes using MS-MLPA were as follows. Two NMCs (Nos. 2, 3) showed methylation of RASSF1a and RASSF1b gene, and one of them (No. 2) also of TP73 gene. By means of MSP, methylation of RASSF1a and RASSF1b gene was found in both cases, while methylation of TP73 gene was absent. All other examined genes (APC, ATM,

Table 5. DNA methylation characteristics of NUT midline carcinomas.

\begin{tabular}{lcccccc}
\hline No & DNA methylation (MS-MLPA) & \multicolumn{3}{c}{ DNA methylation (MSP) } \\
& RASSF1a & RASSF1 $b$ & TP73 & RASSF1a & RASSF1b & TP73 \\
\hline 1 & unmethylated & unmethylated & unmethylated & unmethylated & unmethylated & unmethylated \\
2 & methylated & methylated & methylated & methylated & methylated & unmethylated \\
3 & methylated & methylated & unmethylated & methylated & methylated & unmethylated \\
\hline
\end{tabular}

Abbreviations: MS-MLPA = methylation-specific multiplex ligation-dependent probe amplification; MSP = methylation-specific polymerase chain reaction; NUT $=$ nuclear protein in testis 
BRCA1, BRCA2, CADM1, CASP8, CD44, CDH13, CDKN1B, CDKN2A, CDKN2B, CHFR, DAPK1, ESR1, FHIT, GSTP1, HIC1, KLLN, MLH1a, MLH1b, RARB, TIMP3, and VHL) were unmethylated. The remaining NMC (No. 1) and all control cases of sinonasal mucosa did not feature methylation of any of the abovementioned genes.

Regarding miRNA expression, all NMCs showed upregulation of miR-9 and downregulation of both miR-99a and miR-145, when compared with control cases. In addition, two cases (Nos. 2, 3) showed upregulation of miR-21, miR-143, and miR-484, whereas all these miRNAs were downregulated in the remaining case (No. 1). Neither EBER nor HPV DNA was detected in any of the NMCs.

\section{Discussion}

Sinonasal malignant tumors encompass a heterogeneous group of rarely occurring neoplasms, arising from sinonasal mucosa or seromucinous glands [22]. Their etiopathogenesis remains largely unknown. They are only weakly associated with cigarette smoking but for some subtypes, particularly the intestinal-type adenocarcinoma, occupational exposure to wood dust and various chemical substances, such as nickel, may be a risk factor [23]. Only recently, it has been shown that a significant subset of sinonasal carcinomas, namely squamous cell carcinomas (SCCs), harbor transcriptionally active high-risk human papillomavirus (HPV) infection which was detected in approximately $20-30 \%$ of the cases [21, 24-28]. This finding likely indicates an active role of HPV during carcinogenesis and puts sinonasal carcinomas into the group of HPV-driven neoplasms, which already include cervical, vaginal, vulvar, penile, anal, and oropharyngeal cancers [29-37]. Although the number of types of sinonasal malignancies is already quite high, yet another new tumor entities have been recently described, making the microscopic diagnostics even more challenging [38]. These include NUT midline carcinoma (NMC) $[1,6,8]$, SMARCB1/INI1-deficient carcinoma [39-42], HPV-related carcinoma with adenoid cystic-like features [43], renal cell-like adenocarcinoma [44], and biphenotypic sinonasal sarcoma [45].

In 1991, for the first time, two cases of mediastinal NMC harboring translocation $\mathrm{t}(15 ; 19)$ were reported [46, 47]. Since then, up to 100 cases of NMC have been described, including approximately 40 cases arising in the sinonasal tract $[1,2,6,9]$. Contrary to the initial findings, occurrence of NMC is not limited to children or young individuals but this neoplasm may affect patients of all ages, from newborn to those aged over 80 years, without gender predilection [1, 7-9]. This notion was also observed in the present study - all three patients were older than 40 years. As its name indicates, NMC usually affects midline anatomic areas and organs, such as sinonasal tract, mediastinum, pharynx, larynx or urinary bladder, but may occasionally arise also at other sites, e.g. lungs and salivary glands $[1,2]$.
Table 6. miRNA expression characteristics of NUT midline carcinomas.

\begin{tabular}{lcccccc}
\hline \multirow{2}{*}{ No } & \multicolumn{5}{c}{ miRNA expression (qRT-PCR; $\mathbf{2}^{-\Delta \Delta C t}$ method) } \\
& miR-9 & miR-21 & miR-99a & miR-143 & miR-145 & miR-484 \\
\hline 1 & $\Uparrow 11.22$ & $\Downarrow 0.68$ & $\Downarrow 0.84$ & $\Downarrow 0.18$ & $\Downarrow 0.17$ & $\Downarrow 0.02$ \\
2 & $\Uparrow 23.37$ & $\Uparrow 3.00$ & $\Downarrow 0.44$ & $\Uparrow 2.64$ & $\Downarrow 0.53$ & $\Uparrow 1.48$ \\
3 & $\Uparrow 10.10$ & $\Uparrow 3.38$ & $\Downarrow 0.06$ & $\Uparrow 3.83$ & $\Downarrow 0.85$ & $\Uparrow 2.45$ \\
\hline
\end{tabular}

Abbreviations: $\mathrm{miR}$, miRNA = microRNA; NUT $=$ nuclear protein in testis; qRT-PCR = quantitative real time polymerase chain reaction; $\Uparrow=$ upregulation; $\Downarrow=$ downregulation

NMC typically portends a very poor prognosis, with the median survival less than one year $[1,2]$. In the largest to date study comprising a total of 48 patients [9], the median overall survival was 9.7 months (range; 6.6-15.6 months) and the 2 -year overall survival rate was $30 \%$ (95\% CI; $16-46 \%$ ). Initial surgery with or without adjuvant (chemo)-radiotherapy $(p=0.04)$ and negative resection margins $(p=0.01)$ were the only significant positive prognostic factors. This might explain the highly unusual 108 months survival seen in one patient from the present series, who was diagnosed at an early stage (pT1cN0M0) and treated by radical surgery with negative resection margins and adjuvant radiotherapy.

Grossly, NMC may be well circumscribed, solid, and yellow-tan, with areas of hemorrhage and necrosis [48]. To make its recognition challenging, the microscopic appearance of NMC is not specific. The tumor is composed of sheets and cords of uniform cells with "high grade" features and extremely high mitotic activity. Although diagnostically helpful, abrupt keratinization present in a subset of cases, is usually only a focal finding (as was seen in one our case) and therefore may be absent in a incisional biopsy [1]. Infrequent findings include spindling of tumor cells and presence of a prominent neutrophilic infiltrate [6]. In addition, Nakamura et al. observed two types of tumor cells - small distorted cells with a chromatin-rich nucleus and scant cytoplasm and medium-sized cells with round nuclei, often with prominent nucleoli [49]. On cytological smears, NMC is mostly hypercellular and composed of dyscohesive small to medium-sized cells with round to oval nuclei, devoid of cytoplasm [50]. The immunohistochemical profile of NMC is variable and also not entirely specific. Most of the tumors do express CK5/6, p40, and p63 and therefore were in the past usually diagnosed as poorly differentiated SCCs or sinonasal undifferentiated carcinomas (SNUCs) $[1,6]$. As expression of neuroendocrine markers, e.g. chromogranin and synaptophysin, may be also focally observed, large cell neuroendocrine carcinoma or high grade olfactory neuroblastoma may enter the differential diagnostics [6]. However, with the new monoclonal antibody to the NUT protein, the diagnosis of NMC has become greatly simplified [4]. Nuclear NUT expression (often speckled) in more than $50 \%$ of tumor cells is considered specific for the diagnosis of NMC $[4,6]$. It is our and others experience that the interpretation of the staining is straightforward, the tumors being either diffusely positive 
or completely negative $[4,6]$. Subsequent fluorescence in situ hybridization may be used for confirmation if necessary.

The molecular genetic hallmark of NMC is the presence of $\mathrm{t}(15 ; 19)$ translocation, involving the NUT gene and (mostly) the BRD4 gene [1]. As it is often the sole aberration detected in these tumors, it is considered a very early, possibly tumorinitiating event. Noticeably, we observed the NUT expression also in the "in situ" component present in one of our cases, supporting this hypothesis. The basis for the genesis of the translocation remains, however, unknown. There were found no associations with the exposure to chemical substances or smoking and all NMCs tested negative for HPV and EBV so far $[2,6]$. Interestingly, all SMARCB1/INI1-deficient sinonasal carcinomas tested also negative for NUT expression, indicating that these genetic alterations are mutually exclusive, but the number of analyzed cases is currently too low to draw a definite conclusion [39-42].

To the best of our knowledge, our study is the first one analyzing DNA methylation and miRNA expression in NMC. DNA methylation is one of the most common epigenetic alterations, which significantly contributes to carcinogenesis by silencing tumor suppressor genes [51-54]. In the head and neck cancer, this aberration has been studied by several investigators and compared with HPV status, however, frequently with contradictory results [55-57]. As regards sinonasal tumors, more data on this topic are missing. Only recently, a systematic analysis of DNA methylation in a larger series of sinonasal carcinomas has been published [14]. Chmelarova et al. [14] found significant differences in promoter methylation in CDH13, ESR1, RASSF1, and TP73 genes between malignant tumors and normal sinonasal tissue. In our previous study, we detected methylation of APC, CDH13, RASSF1, TIMP3, and TP73 genes in the SMARCB1/INI1-deficient sinonasal carcinomas [42]. Regarding the present series, two NMCs showed methylation of RASSF1 gene using both MS-MLPA and MSP, while the remaining case was unmethylated. Thus, RASSF1 gene appears to be frequently methylated in sinonasal carcinomas, including NMC. This gene is located on chromosome 3 p21.3 and encodes for a protein which was identified as a tumor suppressor RAS effector implicated in a variety of important biological processes [58]. Through interaction with the protooncogene RAS, it is involved in microtubule stability, apoptosis and cell cycle regulation [58]. The methylation of RASSF1 gene leads to decreased RASSF1 expression as was documented in various cancer types, e.g., non-small cell lung carcinoma, breast carcinoma, and esophageal carcinoma [59-61]. Due to significant mRNA fragmentation and damage in formalin fixed and paraffin embedded tissue, native and/or frozen material is generally needed for assessment of mRNA expression. Therefore, we were not able to test the mRNA expression of RASSF1 gene in our NMC cases. As DNA methylation is reversible, RASFF1 gene may be the target for future personalized therapy [58]. Detailed information on analyzed tumor suppressor genes may be found in the international database "TSGene: Tumor Suppressor Gene Database" (https:// bioinfo.uth.edu/TSGene/).

The research of miRNAs, small non-coding RNAs involved in the regulation of gene expression and carcinogenesis, has drawn a significant attention of many investigators and is currently a hot topic in molecular biology $[12,62]$. Regarding head and neck cancer, miRNAs may be classified into those associated with tumor invasiveness and metastasizing, those functioning as oncogenes, and those related to smoking and HPV infection [12]. A recent review identified 7 consistently upregulated miRNAs (miR-7, miR-21, miR-34, miR-130, miR-155, and miR-223) and 4 consistently downregulated miRNAs (miR-99, miR-100, miR-125, and miR-375) in these malignancies [63]. In addition, both increased expression of miR-18, miR-19, miR-21, miR-134, miR-155, miR-181, and miR-210 and decreased expression of miR-17, miR-34, miR-125, miR-126, miR-153, miR-200, miR-203, mi-R-205, miR-218, miR-363, miR-375, miR-451, and miR-491 were found to be associated with poor prognosis in the head and neck cancer in a meta-analysis by Jamali et al. [64].

On the contrary, the expression pattern of miRNA in sinonasal carcinomas is largely unknown [12]. We are aware of only one study by Ogawa et al. [15] who observed an association between decreased miR-34 expression and a poor disease-specific survival $(p=0.002)$ in patients with sinonasal SCC treated by platinum-based chemotherapy. In the present study, all three NMCs showed upregulation of miR-9 and downregulation of both miR-99 and miR-145. In addition, two of the cases showed upregulation of miR-21, miR-143, and miR-484, whereas all these miRNAs were downregulated in the one remaining case. Among these findings, deregulation of miR-9 and miR-21 expression is of particular interest and might contribute to the dismal prognosis of NMC. For example, upregulation of miR-9 was associated with poor prognosis in patients with both lung carcinoma and osteosarcoma [65] and, similarly, upregulation of miR-21 correlated with poor prognosis in patients with both hematological malignancies, e.g., diffuse large B cell lymphoma and chronic lymphocytic leukemia, and solid cancers, such as carcinomas of breast, lung, large bowel, and prostate [66]. Furthermore, the expression of miR-21 was associated with resistance of these cancer types to drug treatment [66]. The unusual survival of patient No. 2 from our series may be rather due to T1N0M0 stage and R0 resection and not related to miRNA expression profile. Detailed information of validated target genes of miRNAs analyzed so far may be found in the international database "miRBase" (http://www.mirbase.org/).

In summary, we described in depth three cases of NMC identified among a large subset of sinonasal carcinomas and provided detailed molecular genetic analysis. To the best of our knowledge, DNA methylation and miRNA expression was analyzed for the first time in these exceedingly rare tumors. Concerning our results, methylation of RASSF1 gene and deregulation of miR-9, miR-21, miR-99, and miR-145 
are of particular interest and may serve as potential targets for future individualized therapy strategies. On the other hand, as only three NMCs were included in this series, we are fully aware of a fact that our findings might be considered preliminary and should be confirmed by further studies. As clinical trials with BET inhibitors, functioning as acetylhistone mimetics have shown encouraging results both in vitro and in vivo, correct recognition of NMC is crucial for both prognostic and therapeutic purposes.

Acknowledgements: The authors are grateful to Mrs. Y. Rybarova, Mrs. P. Satori, Mrs. E. Skopova, Mrs. E. Smidova, Mrs. J. Sobotkova, and Mrs. M. Valaskova for excellent technical support.

The study was supported by the Charles University Research Development Programs PRVOUK P37/11 and PRVOUK P27/LF1/1, by the Charles University Research Development Program PROGRES Q40/11, by the project BBMRI_CZ LM2015089 (Ministry of Education, Youth and Sports, Czech Republic), by conceptual development of research organization MH CZ-DRO (FNHK) 00179906 (Ministry of Health, Czech Republic), and by European Regional Development Fund-Project BBMRI-CZ.: Biobank network - a versatile platform for the research of the etiopathogenesis of diseases, No: EF16 013/0001674. The funding sources had no involvement in the study design, collection, analysis and interpretation of the data, on the writing of the report, and on the decision to submit the article for publication. The authors declare that they have no conflict of interest.

\section{References}

[1] STELOW EB. A review of NUT midline carcinoma. Head Neck Pathol 2011; 5: 31-35. doi: 10.1007/s12105-010-0235-x

[2] FRENCH CA. Demystified molecular pathology of NUT midline carcinomas. J Clin Pathol 2010; 63: 492-496. doi: 10.1136/jcp.2007.052902

[3] DAVIS BN, KARABAKHTSIAN RG, PETTIGREW AL, ARNOLD SM, FRENCH CA et al. Nuclear protein in testis midline carcinomas: a lethal and underrecognized entity. Arch Pathol Lab Med 2011; 135: 1494-1498. doi: 10.5858/ arpa.2010-0389-CR

[4] HAACK H, JOHNSON LA, FRY CJ, CROSBY K, POLAKIEWICZ RD et al. Diagnosis of NUT midline carcinoma using a NUT-specific monoclonal antibody. Am J Surg Pathol 2009; 33: 984-991. doi: 10.1097/PAS.0b013e318198d666

[5] FRENCH CA, KUTOK JL, FAQUIN WC, TORETSKY JA, ANTONESCU CR et al. Midline carcinoma of children and young adults with NUT rearrangement. J Clin Oncol 2004; 22: 4135-4139.

[6] BISHOP JA, WESTRA WH. NUT midline carcinomas of the sinonasal tract. Am J Surg Pathol 2012; 36: 1216-1221. doi: 10.1097/PAS.0b013e318254ce54

[7] SHEHATA BM, STEELMAN CK, ABRAMOWSKY CR, OLSON TA, FRENCH CA et al. NUT midline carcinoma in a newborn with multiorgan disseminated tumor and a 2-yearold with a pancreatic/hepatic primary. Pediatr Dev Pathol 2010; 13: 481-485. doi: 10.2350/09-10-0727-CR.1
[8] STELOW EB, BELLIZZI AM, TANEJA K, MILLS SE, LEGALLO RD et al. NUT rearrangement in undifferentiated carcinomas of the upper aerodigestive tract. Am J Surg Pathol 2008; 32: 828-834. doi: 10.1097/PAS.0b013e31815a3900

[9] CHAU NG, HURWITZ S, MITCHELL CM, ASERLIND A, GRUNFELD $\mathrm{N}$ et al. Intensive treatment and survival outcomes in NUT midline carcinoma of the head and neck. Cancer 2016; 122: 3632-3640. doi: 10.1002/cncr.30242

[10] CHMELAROVA M, DVORAKOVA E, SPACEK J, LACO J, PALICKA V. Importance of promoter methylation of GATA4 gene in epithelial ovarian cancer. Biomed Pap Med Fac Univ Palacky Olomouc Czech Repub. 2013; 157: 294-297. doi: 10.5507/bp.2013.079

[11] DVORAKOVA E, CHMELAROVA M, LACO J, PALICKA V, SPACEK J. Methylation analysis of tumor suppressor genes in endometrioid carcinoma of endometrium using MSMLPA. Biomed Pap Med Fac Univ Palacky Olomouc Czech Repub. 2013; 157: 298-303. doi: 10.5507/bp.2013.035

[12] KOVǍ̌íKOVÁ H, CHMELAŘOVÁ M, PALIČKA V. [The role of microRNA in head and neck cancer focusing on sinonasal carcinoma]. Cas Lek Cesk 2016; 155: 45-50.

[13] STEPHEN JK, VAUGHT LE, CHEN KM, SETHI S, SHAH $\mathrm{V}$ et al. Epigenetic events underlie the pathogenesis of sinonasal papillomas. Mod Pathol 2007; 20: 1019-1027.

[14] CHMELAŘOVÁ M, SIRÁK I, MŽIK M, SIEGLOVÁ K, VOŠMIKOVÁ $\mathrm{H}$ et al. Importance of tumour suppressor gene methylation in sinonasal carcinomas. Folia Biol 2016; 62: 110-119.

[15] OGAWA T, SAIKI Y, SHIGA K, CHEN N, FUKUSHIGE S et al. miR-34a is downregulated in cis-diamminnedichloroplatinum treated sinonasal squamous cell carcinoma patients with poor prognosis. Cancer Sci 2012; 103:1737-1743. doi: 10.1111/j.1349-7006.2012.02338.x

[16] SOBIN LH, GOSPODAROWICZ MK, WITTEKIND C. Nasal Cavity and Paranasal Sinuses. pp 46-50. In: LH. Sobin, MK. Gospodarowicz, C. Wittekind (Eds.). TNM classification of malignant tumours, 7th Edition. Wiley-Blackwell 2009, p 332. ISBN 978-1-4443-3241-4.

[17] SKÁlOVÁ A, WEINREB I, HYRCZA M, SIMPSON RH, LACO J et al. Clear cell myoepithelial carcinoma of salivary glands showing EWSR1 rearrangement: molecular analysis of 94 salivary gland carcinomas with prominent clear cell component. Am J Surg Pathol 2015; 39: 338-348, doi: 10.1097/PAS.0000000000000364

[18] LACO J, MOTTL R, HÖBLING W, IHRLER S, GROSSMANN P et al. Cyclin D1 expression in ectomesenchymal chondromyxoid tumor of the anterior tongue. Int J Surg Pathol 2016; 24: 586-594. doi: 10.1177/1066896916652221

[19] CHMELAŘOVÁ M, DVOŘÁKOVÁ E, ŠPAČEK J, LACO J, MŽIK M et al. Promoter methylation of GATA4, WIF1, NTRK1 and other selected tumour suppressor genes in ovarian cancer. Folia Biol 2013; 59: 87-92.

[20] SCHMITTGEN TD, LIVAK KJ. Analyzing real-time PCR data by the comparative CT method. Nat Protoc 2008; 3: 1101-1108. 
[21] LACO J, SIEGLOVÁ K, VOŠMIKOVÁ H, DUNDR P, NĚMEJCOVÁ K et al. The presence of high-risk human papillomavirus (HPV) E6/E7 mRNA transcripts in a subset of sinonasal carcinomas is evidence of involvement of HPV in its etiopathogenesis. Virchows Arch 2015; 467: 405-415. doi: $\underline{10.1007 / s 00428-015-1812-\mathrm{x}}$

[22] Nasal cavity and paranasal sinuses. pp. 9-80. In: L. Barnes, JW. Eveson, P. Reichart, S. Sidransky (Eds.). World Health Organization Classification of Tumours. Pathology and Genetics of Head and Neck Tumours. IARC Press, Lyon 2005, p 430. ISBN 978-92-832-2417-4.

[23] 't MANNETJE A, KOGEVINAS M, LUCE D, DEMERS PA, BÉGIN D et al. Sinonasal cancer, occupation, and tobacco smoking in European women and men. Am J Ind Med 1999; 36: 101-107.

[24] EL-MOFTY SK, Lu DW. Prevalence of high-risk human papillomavirus DNA in nonkeratinizing (cylindrical cell) carcinoma of the sinonasal tract: a distinct clinicopathologic and molecular disease entity. Am J Surg Pathol 2005; 29: 13671372.

[25] ALOS L, MOYANO S, NADAL A, ALOBID I, BLANCH JL et al. Human papillomaviruses are identified in a subgroup of sinonasal squamous cell carcinomas with favourable outcome. Cancer 2009; 115: 2701-2709. doi: 10.1002/cncr.24309

[26] BISHOP JA, GUO TW, SMITH DF, WANG H, OGAWA T et al. Human papillomavirus-related carcinomas of the sinonasal tract. Am J Surg Pathol 2013; 37: 185-192. doi: 10.1097/ PAS.0b013e3182698673

[27] LARQUE AB, HAKIM S, ORDI J, NADAL A, DIAZ A et al. High-risk human papillomavirus is transcriptionally active in a subset of sinonasal squamous cell carcinomas. Mod Pathol 2014; 27: 343-351. doi: 10.1038/modpathol.2013.155

[28] TAKAHASHI Y, BELL D, AGARWAL G, ROBERTS D, XIE TX et al. Comprehensive assessment of prognostic markers for sinonasal squamous cell carcinoma. Head Neck 2014; 36: 1094-1102. doi: 10.1002/hed.23423

[29] LACO J, SLANINKA I, JIRÁSEK M, CELAKOVSKY P, VOSMIKOVA $\mathrm{H}$ et al. High-risk human papillomavirus infection and p16INK4a protein expression in laryngeal lesions. Pathol Res Pract 2008; 204: 545-552. doi: 10.1016/j. prp.2008.03.001

[30] LACO J, VOSMIKOVA H, NOVAKOVA V, CELAKOVSKY $\mathrm{P}$, DOLEZALOVA $\mathrm{H}$ et al. The role of high risk human papillomavirus infection in oral and oropharyngeal squamous cell carcinoma in non-smoking and non-drinking patients: a clinicopathological and molecular study of 46 cases. Virchows Arch 2011; 458: 179-187. doi: 10.1007/s00428-010$1037-\mathrm{y}$

[31] LACO J, NEKVINDOVA J, NOVAKOVA V, CELAKOVSKY $\mathrm{P}$, DOLEZALOVA $\mathrm{H}$ et al. Biologic importance and prognostic significance of selected clinicopathological parameters in patients with oral and oropharyngeal squamous cell carcinoma, with emphasis on smoking, protein p16(INK4a) expression, and HPV status. Neoplasma 2012; 59: 398-408. doi: $10.4149 /$ neo 2012052.
[32] de SANJOSÉ S, ALEMANY L, ORDI J, TOUS S, ALEJO M et al. Worldwide human papillomavirus genotype attribution in over 2,000 cases of intraepithelial and invasive lesions of the vulva. Eur J Cancer 2013; 49: 3450-3461. doi: 10.1016/j. ejca.2013.06.033.

[33] ALEMANY L, de SANJOSÉ S, TOUS S, QUINT W, VALLEJOS C et al. Time trends of human papillomavirus types in invasive cervical cancer, from 1940 to 2007. Int J Cancer 2014; 135: 88-95. doi: 10.1002/ijc.28636.

[34] ALEMANY L, SAUNIER M, TINOCO L, QUIRÓS B, ALVARADO-CABRERO I et al. Large contribution of human papillomavirus in vaginal neoplastic lesions: a worldwide study in 597 samples. Eur J Cancer 2014; 50: 2846-2854. doi: 10.1016/j.ejca.2014.07.018

[35] ALEMANY L, SAUNIER M, ALVARADO-CABRERO I, QUIRÓS B, SALMERON J et al. Human papillomavirus DNA prevalence and type distribution in anal carcinomas worldwide. Int J Cancer 2015; 136: 98-107. doi: 10.1002/ ijc. 28963

[36] ALEMANY L, CUBILlA A, HALEC G, KASAMATSU E, QUIRÓS B et al. Role of human papillomavirus in penile carcinomas worldwide. Eur Urol 2016; 69: 953-961. doi: 10.1016/j.eururo.2015.12.007

[37] CASTELLSAGUÉ X, ALEMANY L, QUER M, HALEC G, QUIRÓS B et al. HPV involvement in head and neck cancers: comprehensive assessment of biomarkers in 3680 cases. J Natl Cancer Inst 2016; 108: djv403. doi: 10.1093/jnci/ djv403.

[38] BISHOP JA. Newly described tumor entities in sinonasal tract pathology. Head Neck Pathol 2016; 10: 23-31. doi: 10.1007/s12105-016-0688-7

[39] AGAIMY A, KOCH M, LELL M, SEMRAU S, DUDEK W et al. SMARCB1(INI1)-deficient sinonasal basaloid carcinoma: a novel member of the expanding family of SMARCB1-deficient neoplasms. Am J Surg Pathol 2014; 38: 1274-1281. doi: $\underline{10.1097 / \text { PAS.0000000000000236 }}$

[40] BISHOP JA, ANTONESCU CR, WESTRA WH. SMARCB1 (INI-1)-deficient carcinoma of the sinonasal tract. Am J Surg Pathol 2014; 38: 1282-1289. doi: 10.1097/ PAS.0000000000000285

[41] BELL D, HANNA EY, AGAIMY A, WEISSFERDT A. Reappraisal of sinonasal undifferentiated carcinoma: SMARCB1 (INI1)-deficient sinonasal carcinoma: a single-institution experience. Virchows Arch 2015; 467: 649-656. doi: 10.1007/ s00428-015-1853-1

[42] LACO J, CHMELAŘOVÁ M, VOŠMIKOVÁ H, SIEGLOVÁ K, BUBANCOVÁ I et al. SMARCB1/INI1-deficient sinonasal carcinoma shows methylation of RASSF1 gene: a clinicopathological, immunohistochemical and molecular genetic study of a recently described entity. Pathol Res Pract 2017; 213: 133-142. doi:10.1016/j.prp.2016.10.012.

[43] BISHOP JA, OGAWA T, STELOW EB, MOSKALUK CA, $\mathrm{KOCH} \mathrm{WM}$ et al. Human papillomavirus-related carcinoma with adenoid cystic-like features: a peculiar variant of head and neck cancer restricted to the sinonasal tract. Am J Surg Pathol 2013; 37: 836-844. doi: 10.1097/ $\underline{\text { PAS.0b013e31827b1cd6 }}$ 
[44] ZUR KB, BRANSWEIN M, WANG B, SOM P, GORDON $\mathrm{R}$ et al. Primary description of a new entity, renal cell-like carcinoma of the nasal cavity: van Meegeren in the house of Vermeer. Arch Otolaryngol Head Neck Surg 2002; 128: 441-447.

[45] LEWIS JT, OLIVEIRA AM, NASCIMENTO AG, SCHEMBRI-WISMAYER D, MOORE EA et al. Low-grade sinonasal sarcoma with neural and myogenic features: a clinicopathologic analysis of 28 cases. Am J Surg Pathol 2012; 36: 517525. doi: 10.1097/PAS.0b013e3182426886

[46] KEES UR, MULCAHY MT, WILLOUGHBY ML. Intrathoracic carcinoma in an 11-year-old girl showing a translocation $\mathrm{t}(15 ; 19)$. Am J Pediatr Hematol Oncol 1991; 13: 459464.

[47] KUBONISHI I, TAKEHARA N, IWATA J, SONOBE H, OHTSUKI Y et al. Novel $\mathrm{t}(15 ; 19)(\mathrm{q} 15 ; \mathrm{p} 13)$ chromosome abnormality in a thymic carcinoma. Cancer Res 1991; 51: 3327-3328.

[48] WASSERMAN JK, PURGINA B, SEKHON H, GOMES $\mathrm{MM}$, LAI C. The gross appearance of a NUT midline carcinoma. Int J Surg Pathol 2016; 24: 85-88. doi: $\underline{10.1177 / 1066896915606970}$

[49] NAKAMURA H, TSUTA K, TSUDA H, KATSUYA Y, NAKA G. NUT midline carcinoma of the mediastinum showing two types of poorly differentiated tumor cells: a case report and a literature review. Pathol Res Pract 2015; 211: 92-98. doi: 10.1016/j.prp.2014.07.006

[50] BISHOP JA, FRENCH CA, ALI SZ. Cytopathologic features of NUT midline carcinoma: a series of 26 specimens from 13 patients. Cancer Cytopathol 2016; doi: 10.1002/cncy.21761

[51] CHMELAŘOVÁ M, KŘEPINSKÁ E, SPAČEK J, LACO J, NEKVINDOVÁ J et al. Methylation analysis of tumor suppressor genes in ovarian cancer using MS-MLPA. Folia Biol 2012; 58: 246-250.

[52] CHMELAROVA M, KREPINSKA E, SPACEK J, LACO J, BERANEK $\mathrm{M}$ et al. Methylation in the p53 promoter in epithelial ovarian cancer. Clin Transl Oncol 2013; 15: 160-163. doi: 10.1007/s12094-012-0894-Z

[53] CHMELAROVA M, KOS S, DVORAKOVA E, SPACEK $\mathrm{J}$, LACO $\mathrm{J}$ et al. Importance of promoter methylation of GATA4 and TP53 genes in endometrioid carcinoma of endometrium. Clin Chem Lab Med 2014; 52: 1229-1234, doi: 10.1515/cclm-2013-0162

[54] MŽIK M, CHMELAŘOVÁ M, JOHN S, LACO J, SLABÝ $\mathrm{O}$ et al. Aberrant methylation of tumour suppressor genes WT1, GATA5 and PAX5 in hepatocellular carcinoma. Clin Chem Lab Med 2016; 54: 1971-1980. doi: 10.1515/cclm$\underline{2015-1198}$
[55] TALUKDAR FR, GHOSH SK, LASKAR RS, KANNAN R, CHOUDHURY B et al. Epigenetic pathogenesis of human papillomavirus in upper aerodigestive tract cancers. Mol Carcinog 2015; 54: 1387-1396, doi: 10.1002/mc.22214

[56] CHOUDHURY JH, GHOSH SK. Promoter hypermethylation profiling identifies subtypes of head and neck cancer with distinct viral, environmental, genetic and survival characteristics. PLoS One 2015; 10: e0129808. doi: 10.1371/journal.pone. 0129808

[57] DONG SM, SUN DI, BENOIT NE, KUZMIN I, LERMAN MI et al. Epigenetic inactivation of RASSF1A in head and neck cancer. Clin Cancer Res 2003; 9: 3635-3640.

[58] FERNANDES MS, CARNEIRO F, OLIVEIRA C, SERUCA R. Colorectal cancer and RASSF family - a special emphasis on RASSF1A. Int J Cancer 2013; 132: 251-258. doi: 10.1002/ ijc. 27696

[59] PASTUSZAK-LEWANDOSKA D, KORDIAK J, MIGDALSKA-SEK M, CZARNECKA KH, ANTCZAK A, GÓRSKI P et al. Quantitative analysis of mRNA expression levels and DNA methylation profiles of three neighboring genes: FUS1, NPRL2/G21 and RASSF1A in non-small cell lung cancer patients. Respir Res 2015; 16:76. doi: 10.1186/s12931-015$\underline{0230-6}$

[60] HAGRASS HA, PASHA HF, SHAHEEN MA, ABDEL BARY EH, KASSEM R. Methylation status and protein expression of RASSF1A in breast cancer patients. Mol Biol Rep 2014; 41:57-65. doi: 10.1007/s11033-013-2837-3

[61] MAO WM, LI P, ZHENG QQ, WANG CC, GE MH et al. Hypermethylation-modulated downregulation of RASSF1A expression is associated with the progression of esophageal cancer. Arch Med Res 2011; 42: 182-188. doi: 10.1016/j.arcmed.2011.04.002

[62] KALFERT D, PESTA M, KULDA V, TOPOLCAN O, RYSKA A et al. MicroRNA profile in site-specific head and neck squamous cell cancer. Anticancer Res 2015; 35: 2455-2463.

[63] CHEN D, CABAY RJ, JIN Y, WANG A, LU Y et al. MicroRNA deregulations in head and neck squamous cell carcinomas. J Oral Maxillofac Res 2013; 4: e2. doi: 10.5037/jomr.2013.4102

[64] JAMALI Z, AMINABADI NA, ATTARAN R, POURNAGIAZAR F, OSKOUEI SG et al. MicroRNAs as prognostic molecular signatures in human head and neck squamous cell carcinoma: a systematic review and meta-analysis. Oral Oncol 2015; 51: 321-331. doi: 10.1016/j.oraloncology.2015.01.008

[65] SUN H, SHAO Y, HUANG J, SUN S, LIU Y et al. Prognostic value of microRNA-9 in cancers: a systematic review and meta-analysis. Oncotarget 2016; doi: 10.18632/oncotarget.

[66] FENG YH, TSAO CJ. Emerging role of microRNA-21 in cancer (review). Biomed Rep 2016; 5: 395-402. 